\title{
Comment on "Magnetic relaxation of interacting co clusters: Crossover from two- to
} three-dimensional lattices"

\author{
Hansen, Mikkel Fougt; Mørup, Steen
}

Published in:

Physical Review Letters

Link to article, DOI:

10.1103/PhysRevLett.90.059705

Publication date:

2003

Document Version

Publisher's PDF, also known as Version of record

Link back to DTU Orbit

Citation (APA):

Hansen, M. F., \& Mørup, S. (2003). Comment on "Magnetic relaxation of interacting co clusters: Crossover from two- to three-dimensional lattices". Physical Review Letters, 90(5), 059705.

https://doi.org/10.1103/PhysRevLett.90.059705

\section{General rights}

Copyright and moral rights for the publications made accessible in the public portal are retained by the authors and/or other copyright owners and it is a condition of accessing publications that users recognise and abide by the legal requirements associated with these rights.

- Users may download and print one copy of any publication from the public portal for the purpose of private study or research.

- You may not further distribute the material or use it for any profit-making activity or commercial gain

- You may freely distribute the URL identifying the publication in the public portal 
Comment on "Magnetic Relaxation of Interacting Co Clusters: Crossover from Two- to Three-Dimensional Lattices"

In a recent Letter, Luis et al. [1] have studied superparamagnetic relaxation phenomena in samples with layers of $\mathrm{Co}$ nanoparticles in $\mathrm{Al}_{2} \mathrm{O}_{3}$. It was shown that the blocking temperature, estimated from ac susceptibility measurements, increases when the number of layers of Co nanoparticles increases; i.e., the relaxation is slowed down because of dipole-dipole interactions. The results were explained by an increase of the single particle energy barriers due to dipole-dipole interactions.

The model used by Luis et al. [1] excludes collective dynamics of the particle moments and a transition to an ordered state at a finite temperature. In this Comment, we argue that their analysis is based on unrealistic assumptions, and we suggest an alternative interpretation of their data in terms of collective dynamics.

Luis et al. [1] wrote the expression for the relaxation time

$$
\tau_{ \pm}=\tau_{0} \exp \left[\left(U_{0} \pm E_{\mathrm{dip}}\right) / k_{\mathrm{B}} T\right]
$$

where $U_{0}$ is the anisotropy energy barrier in the absence of interactions, $E_{\mathrm{dip}}$ is the dipole interaction energy, and + and - correspond, respectively, to reversal against and towards the local dipolar field created by the neighboring particles. Inspired by the model by Dormann et al. [2], the authors assumed that the neighbors have time to relax to their equilibrium state, such that the central spin always has to relax against the dipolar field. This results in a larger effective energy barrier and thereby a longer relaxation time than for noninteracting spins. The assumption may be correct if the central spin interacts weakly with its neighbors and relaxes much slower than its neighbors. Thus, the model may be a fair approximation for the relaxation of the largest particles in a sample with a broad particle size distribution and weak interactions [3]. However, Luis et al. [1] considered an average particle in a sample with a narrow particle size distribution where all particles have similar relaxation times, and therefore the assumption is not fulfilled.

Several studies of dipole-interacting systems have shown that strong dipole interactions can result in a transition to an ordered state of otherwise superparamagnetic particles [4-8]. For a sample with a narrow particle size distribution and strong interactions, the transition to the ordered state may be a true second order phase transition accompanied by a critical divergence of the longest collective relaxation time [4-8]. For samples with weaker interactions or a wider size distribution, the dynamics may be a complex interplay between collective dynamics of some particles and other particles being thermally blocked. In this case, a true phase transition may be absent although collective effects still play an important role [7,9]. It has been shown [3] that the correct order of magnitude of the temperature, $T_{c r}$, at which collective effects set in is

$$
T_{\mathrm{c} r} \sim \mu_{0} \mu^{2} /\left(4 \pi r^{3} k_{\mathrm{B}}\right),
$$

where $\mu$ is the magnetic moment of a particle of average size and $r$ is the average interparticle distance. In the present study, the cobalt particles have a diameter of $2.9 \mathrm{~nm}$ and $r \approx 5 \mathrm{~nm}$. Inserting in Eq. (2) one finds that $T_{\mathrm{c} r} \sim 30 \mathrm{~K}$. The authors report that the paramagnetic Curie temperature increases from $\theta=5 \mathrm{~K}$ for one cobalt layer to $\theta=40 \mathrm{~K}$ for 20 cobalt layers [1]. This increase by $35 \mathrm{~K}$ can only be due to interparticle interactions and, at least for ferromagnetic ordering, it would indicate an ordering temperature of $\approx 30-40 \mathrm{~K}$. This strongly suggests that collective phenomena play a significant role for the magnetic dynamics in the samples. We suggest that the experimentally observed interaction-induced changes of the relaxation time could be interpreted in terms of a transition from 2D to 3D collective dynamics.

Mikkel F. Hansen*

Mikroelektronik Centret (MIC)

Technical University of Denmark (DTU)

Building 345 east

DK-2800 Kongens Lyngby, Denmark

Steen Mørup

Department of Physics

Technical University of Denmark (DTU)

Building 307

DK-2800 Kongens Lyngby, Denmark

Received 28 June 2002; published 7 February 2003

DOI: 10.1103/PhysRevLett.90.059705

PACS numbers: 75.50.Tt, 75.40.Gb, 75.50.Lk

*Electronic address: mfh@mic.dtu.dk

[1] F. Luis et al., Phys. Rev. Lett. 88, 217205 (2002).

[2] J. L. Dormann, L. Bessais, and D. Fiorani, J. Phys. C 21, 2015 (1988).

[3] M. F. Hansen and S. Mørup, J. Magn. Magn. Mater. 184, 262 (1998).

[4] C. Djurberg et al., Phys. Rev. Lett. 79, 5154 (1997).

[5] J. L. Dormann et al., J. Magn. Magn. Mater. 187, L139 (1998).

[6] H. Mamiya and I. Nakatani, Nanostruct. Mater. 12, 859 (1999).

[7] M. F. Hansen et al., J. Phys. Condens. Matter 14, 4901 (2002).

[8] O. Petracic et al., Phase Transit. 75, 73 (2002).

[9] T. Jonsson, P. Nordblad, and P. Svedlindh, Phys. Rev. B 57, 497 (1998). 